\title{
SONOCHEMICAL SYNTHESIS OF HEMATITE NANOPARTICLES
}

\author{
Mihail Iacob \\ "Petru Poni" Institute of Macromolecular Chemistry, 41A, Grigore Ghica Voda Alley, Iasi, Romania \\ Institute of Chemistry of the Academy of Sciences of Moldova, 3, Academiei str., 2028 Chisinau, Republic of Moldova \\ e-mail: iacob.mihai@icmpp.ro
}

\begin{abstract}
Hematite nanoparticles were prepared by a procedure consisting in sonication of $\mu_{3}$-oxo trinuclear iron(III) acetate of composition $\left[\mathrm{Fe}_{3} \mathrm{O}\left(\mathrm{OOCCH}_{3}\right)_{6}\left(\mathrm{H}_{2} \mathrm{O}\right)_{3}\right] \mathrm{NO}_{3} \cdot 4 \mathrm{H}_{2} \mathrm{O},\left\{\mathrm{Fe}_{3} \mathrm{O}\right\} \mathrm{NO}_{3}$ as iron source, in strong basic conditions followed by thermal treatment at $600^{\circ} \mathrm{C}$. The formation of the hematite was confirmed by IR spectroscopy, X-ray powder diffraction and Raman spectroscopy while, the shape and size of the nanoparticles and their agglomeration were evidenced and estimated on the basis of the images taken with TEM techniques.
\end{abstract}

Keywords: hematite, nanoparticles, iron oxides, sonochemistry.

Received: July 2014/ Revised final: September 2014/ Accepted: September 2014

\section{Introduction}

Iron oxide based nanomaterials attracted attention of researchers due to their interesting properties and large applicability in various areas such as: diagnostic agents in magnetic resonance imaging (MRI) [1,2], magnetic hyperthermia [2], drug delivery [3], immunoassay [4], magnetic separation [5], and magneto-caloric refrigeration [6].

There are various forms of iron oxides [7]. They differ in composition, in the valence of $\mathrm{Fe}$ and, above all, in crystal structure. The most stable and wide spread oxide phase of iron is $\alpha-\mathrm{Fe}_{2} \mathrm{O}_{3}$, where $\mathrm{Fe}$ has the lower Gibbs free energy [8]. Hematite has hexagonal structure of the corundum type with a close-packed oxygen lattice in which twothirds of the octahedral sites are occupied by $\mathrm{Fe}(\mathrm{III})$ ions. Bulk hematite is antiferromagnetic till Morin temperature (TM) ( 260 K). Between TM and Neel temperature (TN) $(\sim 950 \mathrm{~K})$ it is weak ferromagnetic and above TN the hematite is paramagnetic [9,11]. These transitions are influenced by particle size, shape and crystallinity [9-11]. Particles smaller than $16 \mathrm{~nm}$ have a superparamagnetic behaviour at room temperature [12].

Hematite nanoparticles proved to be effective catalyst in numerous reactions such as the decomposition of soot and $\mathrm{NO}_{\mathrm{x}}$ in diesel exhausts [13], oxidation of $\mathrm{CO}$ [14], photocatalytic degradation of salicylic acid [15], and FischerTropsch synthesis [16]. An iron-based solid catalyst is also normally used as a Lewis acid catalyst and/or support in homogeneous and heterogeneous catalysis [17]. Hematite nanoparticles could be applicable in water treatment technology for removing metal [18]. Hematite has a bandgap of 2-2.2 eV thus being semiconductor suitable for photocatalytic water-splitting with hydrogen formation [19].

The hematite nanoparticles could be obtained by different routes: co-precipitation [20], microemulsion method [20,21], thermal decomposition [20,22], sol-gel method [23], ball milling [24], green synthesis method [25], sonochemical synthesis [26], forced hydrolysis [20,27,28], hydrothermal and solvothermal method [17,20,29].

Different iron sources for hematite nanoparticles are reported in literature: iron(III) chlorides $\left(\mathrm{FeCl}_{2}\right.$ and $\left.\mathrm{FeCl}_{3}\right)$ [21, 23, 27-29], ferrocene [22], iron(III) nitrate [17, 25], ferrous sulfate [30], iron pentacarbonyl [26], etc.

Our approach in this study is to obtain hematite nanoparticles using $\mu_{3}$-oxo homotrinuclear $\left\{\mathrm{Fe}_{3} \mathrm{O}\right\} \mathrm{NO}_{3}$ acetate as an iron source and easy sonochemical route as a synthesis procedure. The obtained product was characterized by adequate techniques (FTIR, energy-dispersive X-ray spectroscopy, Raman spectroscopy, wide angle X-ray spectroscopy, transmission electron microscopy), in order to evaluate the formed structure.

\section{Experimental \\ Materials}

$\mu_{3}$-oxo trinuclear iron(III) acetate $\left(\left[\mathrm{Fe}_{3} \mathrm{O}\left(\mathrm{CH}_{3} \mathrm{COO}\right)_{6}\left(\mathrm{H}_{2} \mathrm{O}\right)_{3}\right] \mathrm{NO}_{3} \cdot 4 \mathrm{H}_{2} \mathrm{O}\right)$ was prepared through an already reported procedure [31] by using $\mathrm{Fe}\left(\mathrm{NO}_{3}\right)_{3} \cdot 9 \mathrm{H}_{2} \mathrm{O}$ (Sigma-Aldrich) and sodium acetate $\left(\mathrm{CH}_{3} \mathrm{COONa}\right.$ ) (Sigma-Aldrich), glacial acetic acid (Chemical Company), and distilled water. Structure of the compound was verified by FTIR (Figure 1, IA) and XRD (literature [31]: $\mathrm{a}=15.69(3), \mathrm{b}=11.77(2), \mathrm{c}=15.32(4) \AA)$; obtained: $\mathrm{a}=15.65, \mathrm{~b}=11.765, \mathrm{c}=15.31 \AA$ ) FTIR $v_{\text {max }}(\mathrm{KBr}), \mathrm{cm}^{-1}: 420 \mathrm{vw}, 468 \mathrm{vw}, 527 \mathrm{w}, 613 \mathrm{~s}, 662 \mathrm{~s}, 822 \mathrm{w}, 835 \mathrm{w}, 898 \mathrm{vw}, 951 \mathrm{w}, 1035 \mathrm{~m}, 1292 \mathrm{~s}, 1385 \mathrm{vs}$, $1450 \mathrm{vs}, 1589 \mathrm{vs}, 1688 \mathrm{~s}, 2545 \mathrm{vw}, 2636 \mathrm{vw}, 3413 \mathrm{~s}$.

\section{Equipments}

An Energy Dispersive X-Ray system (EDX) available on Environmental Scanning Electron Microscope (ESEM) type Quanta 200 was also used for qualitative analysis and elemental mapping.

The infrared spectra were registered on a Bruker Vertex 70 FT-IR instrument, in transmission mode, in the 300$4000 \mathrm{~cm}^{-1}$ range (resolution $2 \mathrm{~cm}^{-1}, 32$ scans), at ambient temperature.

The Raman spectra were recorded with a Renishaw InVia Reflex spectrometer, equipped with a $632.8 \mathrm{~nm}$ HeNe laser as excitation source. A 50x objective lens with $\mathrm{NA}=0.75$ of a Leica DM $2500 \mathrm{M}$ microscope was used to 
focus the laser beam on the sample and collect the backscattered Raman signal. The investigated spectral region was $100-1000 \mathrm{~cm}^{-1}$, at low incident laser power selected in order to avoid sample degradation. For a high signal to noise ratio, the exposure time and accumulation number were optimized.

Transmission Electron Microscopy (TEM) investigation was made with Hitachi High-Tech HT7700 Transmission Electron Microscope operated at $100 \mathrm{kV}$ accelerating voltage in high contrast mode. The samples were prepared on carbon coated copper grids of 200 mesh size. Microdrops of the nanoparticles dispersed in water $(0.1 \%)$ were placed on the grids, and then solvent was removed in vacuum.

Scanning electron microscope (SEM) images were acquired with an electronic microscope (ESEM) type Quanta 200 operating at $30 \mathrm{kV}$ with secondary and backscattering electrons in high vacuum mode.

Wide Angle X-rays Diffraction (WAXD) was performed on a Bruker-AXS D8 ADVANCE diffractometer, with Bragg Brentano parafocusing goniometer. Scans were recorded in step mode using Ni-filtered $\mathrm{Cu} \mathrm{K} \alpha$ radiation $\lambda=0.1541 \mathrm{~nm}$. The working conditions were $40 \mathrm{kV}$ and $30 \mathrm{~mA}$ tube power. The Bruker computer software Eva 11 and Topaz 3.1 were used to plot and process the data.

\section{Preparation of hematite nanoparticles (NPs)}

The $\mu_{3}$-oxo heterotrinuclear $\left\{\mathrm{Fe}_{3} \mathrm{O}\right\}$ acetate $\left(\left[\mathrm{Fe}_{3} \mathrm{O}\left(\mathrm{CH}_{3} \mathrm{COO}\right)_{6}\left(\mathrm{H}_{2} \mathrm{O}\right)_{3}\right] \mathrm{NO}_{3} \cdot 4 \mathrm{H}_{2} \mathrm{O}\right)(1.00 \mathrm{~g}, 1.38 \mathrm{mmol})$ was dissolved in $5 \mathrm{~mL}$ distilled water and ultrasonicated for $5 \mathrm{~min}$ at room temperature. To this, $5 \mathrm{~mL}$ of $25 \mathrm{M} \mathrm{NaOH}$ solution was added. The obtained mixture was ultrasonicated for another $30 \mathrm{~min}$ (UTR200, 200w, 24KHz). The purification of the product was done by washing with distilled water until the $\mathrm{pH}$ reaches neutral value. After that it was calcinated for $10 \mathrm{~h}$ at $600{ }^{\circ} \mathrm{C}$. The final product was obtained as a red fine-crystalline mass.

\section{Results and discussion}

Iron oxide, NPs, have been prepared by a procedure consisting in the decomposition of $\mu_{3}$-oxo trinuclear iron(III) acetate, $\left\{\mathrm{Fe}_{3} \mathrm{O}\right\} \mathrm{NO}_{3}$, by sonication in strong alkaline aqueous medium $(\mathrm{pH}=11.7)$, followed by neutralization and calcination, as is illustrated in Scheme 1. The water molecules are eliminated and acetate groups are decomposed. It is assumed that during these processes the Fe-O bonds in iron(III) oxide molecules are preserved. The oxide molecules are agglomerated in nanoparticles (NPs) of different sizes.

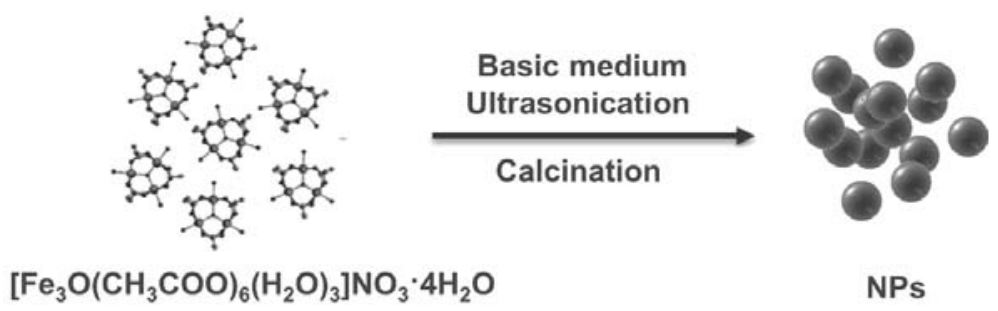

\section{Scheme 1. A graphical representation of the pathway leading to iron oxide nanoparticles.}

The infrared spectrum of nanoparticles, NPs, as compared with that for $\left\{\mathrm{Fe}_{3} \mathrm{O}\right\} \mathrm{NO}_{3}$ cluster, (Figure 1) reveals the almost complete disappearance of acetate and nitrate anions, water, and iron-ligand vibrations present in the spectrum of iron acetate. The bands at 552, 474, 446, $384 \mathrm{~cm}^{-1}$ could be assigned to $\mathrm{Fe}-\mathrm{O}$ vibrations, characteristic for hematite according to literature data [32].

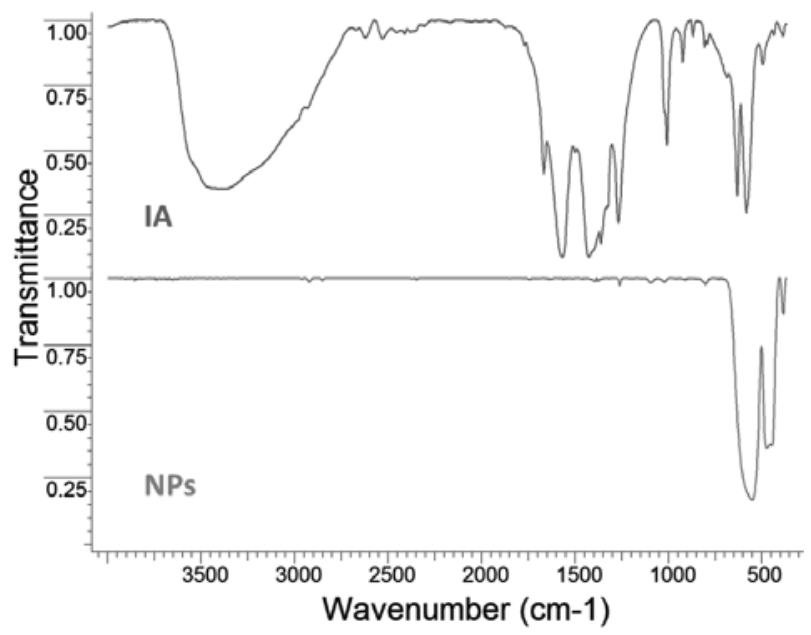

Figure 1. FTIR spectra of $\left\{\mathrm{Fe}_{3} \mathrm{O}\right\} \mathrm{NO}_{3}$ acetate (IA) and obtained nanoparticles (NPs). 


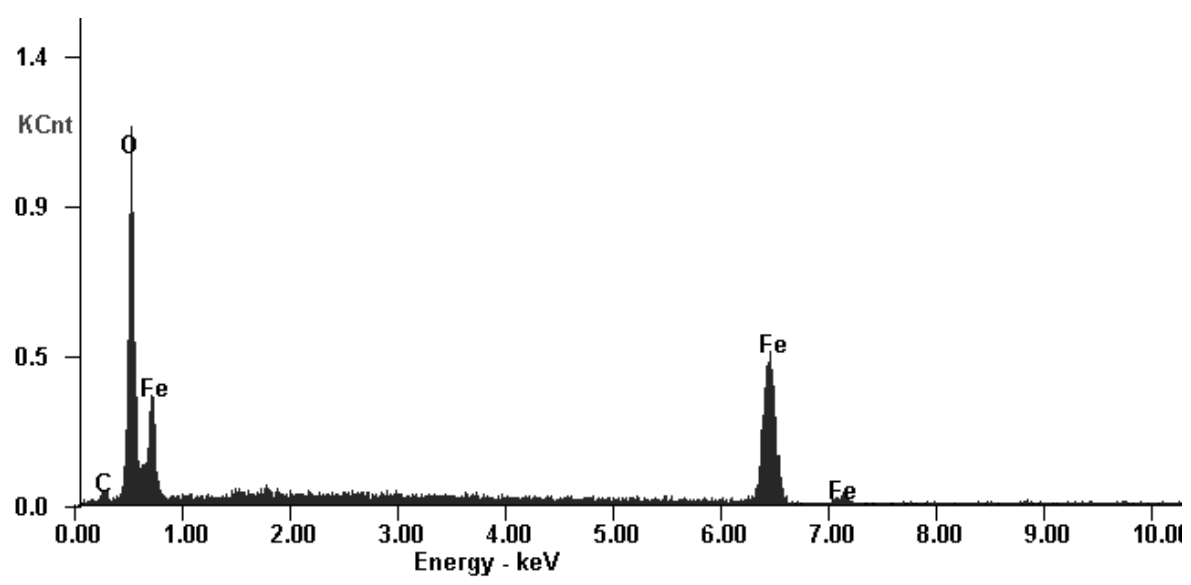

Figure 2. EDX spectrum for NPs.

The presence of iron and oxygen in the prepared material is clearly revealed by EDX analysis (Figure 2). The peak with a low intensity which corresponds to carbon, is attributed to the substrate.

TEM images (Figure 3) were taken on water-dispersed nanoparticles sprayed on carbon coated copper grid and glass substrate, respectively. From Figure $3 \mathrm{a}$ it can be observed that particles have irregular shape. Images were processed with ImageJ 3.0 [33] to obtain the derived histogram (Figure 3b) and, according to these, the agglomerated particles size are in the range $10-40 \mathrm{~nm}$ with the main diameter of about $20 \mathrm{~nm}$.
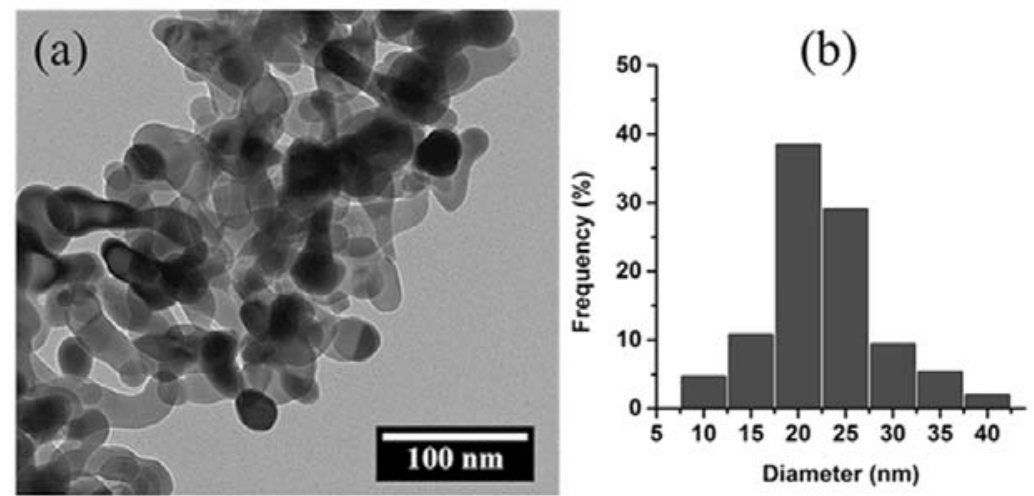

Figure 3. TEM images of nanoparticles (a) and size distribution of nanoparticles (histogram) (b).

Wide Angle X-ray powder diffraction was measured on the obtained material at room temperature in the range $20-70\left(2 \theta^{\circ}\right)$. The found XRD patterns (Figure 4) revealed good crystallinity and the peak assignment made according to literature data corresponds to well established structure of hematite as shown in Table 1 [34]. Appling Scherrer formula [35], the crystallite size was calculated as being $15 \mathrm{~nm}$.

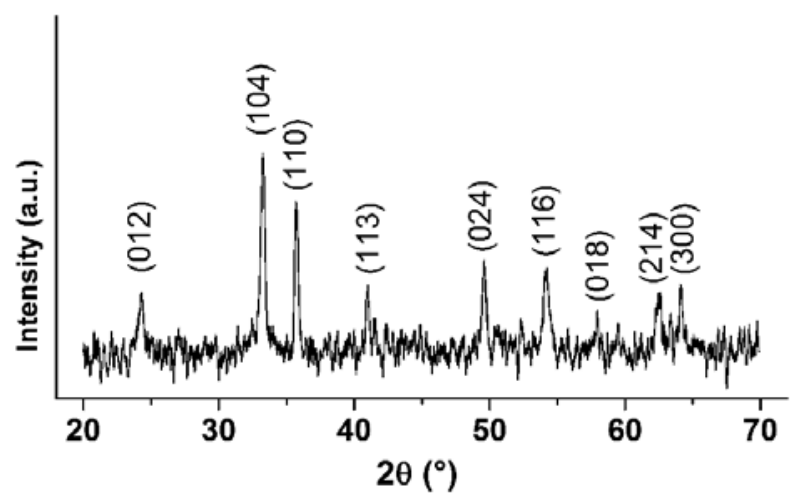

Figure 4. X-ray powder diffraction pattern of nanoparticles. 
The peak assignment of NPs in comparison with literature data [34].

\begin{tabular}{llll}
\hline & $N P S$ & & \multicolumn{2}{c}{ Literature data } \\
\hline $2 \theta\left(^{\circ}\right)$ & $d(\AA)$ & $2 \theta\left(^{\circ}\right)$ & $d(\AA)$ \\
\hline 24.27 & 3.67 & 24.17 & 3.68 \\
33.25 & 2.69 & 33.19 & 2.70 \\
35.71 & 2.51 & 35.67 & 2.52 \\
40.91 & 2.21 & 40.91 & 2.21 \\
49.54 & 1.84 & 49.52 & 1.84 \\
54.34 & 1.69 & 54.13 & 1.70 \\
57.96 & 1.59 & 57.66 & 1.60 \\
62.45 & 1.49 & 62.51 & 1.49 \\
64.04 & 1.45 & 64.08 & 1.45 \\
\hline
\end{tabular}

The Raman spectrum of nanoparticles is shown in Figure 5. In this spectrum the signatures specific for hematite are visible: there are two $\mathrm{A}_{1 \mathrm{~g}}$ modes $\left(222\right.$ and $\left.493 \mathrm{~cm}^{-1}\right)$ and four $\mathrm{E}_{\mathrm{g}}$ modes $\left(241,289,404,607 \mathrm{~cm}^{-1}\right)$, and longitudinal optical (LO) $\mathrm{E}_{\mathrm{u}}$ mode $\left(656 \mathrm{~cm}^{-1}\right)[36,37]$. Thus, the data from the Raman spectrum confirmed the presence of $\alpha-\mathrm{Fe}_{2} \mathrm{O}_{3}$ (hematite) as it was identified through WAXD.

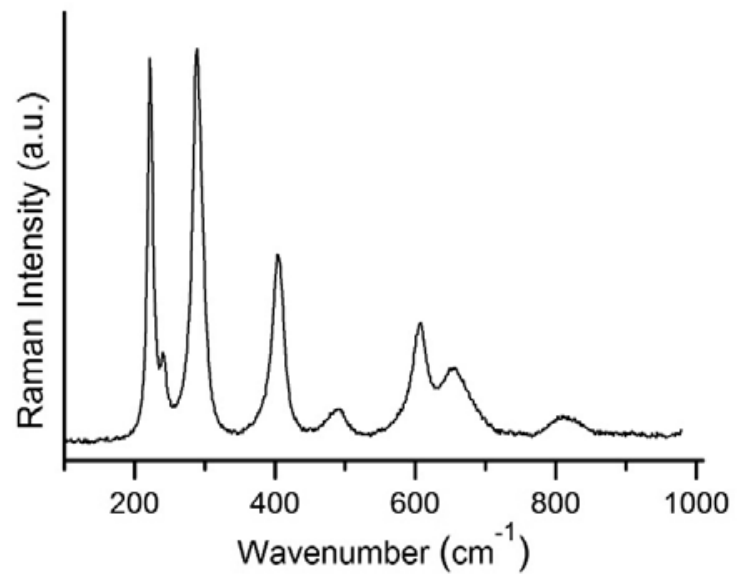

Figure 5. Raman spectrum of nanoparticles.

\section{Conclusions}

Sonochemistry followed by thermal decomposition has been proved to be an efficient route to iron oxide nanoparticles starting from $\mu_{3}$-oxo trinuclear iron(III) acetate as a metal source. The chemical nature of the reaction medium (basic $\mathrm{pH}$ ) together with some physical factors (e.g., temperature), favored the formation of the hematite species of the iron oxide as has been demonstrated by WAXD analysis and confirmed by Raman and FTIR spectroscopy. The size of agglomerated nanoparticles estimated on the basis of TEM images was found to be in the range 10-40 nm, but applying Scherrer formula, the crystallite size was calculated as being $15 \mathrm{~nm}$.

\section{Acknowledgments}

This work was supported by a grant of the Ministry of National Education, CNCS - UEFISCDI, Program PNII-Capacities, Modul III, Romania - Moldova Bilateral Cooperation (Project ComSilBio, Contract 690/16.04.2013), national project number No. 14.518.02.05A and project No. 11.817.08.24A.

\section{References}

1. Xu, F.; Cheng, C.; Chen, D.-X.; Gu, H. Magnetite Nanocrystal Clusters with Ultra-High Sensitivity in Magnetic Resonance Imaging. ChemPhysChem, 2012, 13, pp. 336 - 341.

2. Maity, D.; Chandrasekharan, P.; Yang, C.-T.; Chuang, K.-H.; Shuter, B.; Xue, J.-M.; Ding, J.; Feng, S.-S. Facile synthesis of water-stable magnetite nanoparticles for clinical MRI and magnetic hyperthermia applications. Nanomedicine, 2010, 5(10), pp. 1571-1584. 
3. Guo, M.; Yan, Y.; Liu, X.; Yan, H.; Liu, K.; Zhang, H.; Cao, Y. Multilayer nanoparticles with a magnetite core and a polycation inner shell as pH-responsive carriers for drug delivery. Nanoscale, 2010, 2, pp. 434-441.

4. Zhang, G.; Liu, Y.; Zhang, C.; Hu, W.; Xu, W.; Li, Z.; Liang, S.; Cao, J.; Wang, Y. Aqueous immune magnetite nanoparticles for immunoassay. Journal of Nanoparticle Research, 2009, 11, pp. 441-448.

5. Sayin, S.; Ozcan, F.; Yilmaz. M. Two novel calixarene functionalized iron oxide magnetite nanoparticles as a platform for magnetic separation in the liquid-liquid/solid-liquid extraction of oxyanions. Materials Science and Engineering C, 2013, 33, pp. 2433-2439.

6. Hariharan, S.; Gass J. Superparamagnetism and Magneto-Caloric Efect (MCE) in Functional Magnetic Nanostrucutres. Reviews on Advanced Materials Science, 2005, 10, pp. 298-402.

7. Schwertmann, U.; Cornell, R.M. Iron Oxides in the Laboratory. Preparation and Characterization. Second, Completely Revised and Extended Edition. Wiley-VCH: Weinheim, 2000, 188p.

8. Schmid, G. Nanoparticles from Theory to Application. Second Edition. Wiley-VCH: Weinheim, 2010, 522p.

9. Zysler, R.D.; Vasquez-Mansilla, M.; Arciprete, C.; Dimitrijewits, M.; Rodriguez-Sierra, D.; Saragovi, C. Structure and magnetic properties of thermally treated nanohematite. Journal of Magnetism and Magnetic Materials, 2001, 224, pp. 39-48.

10. Can, M.M.; Fırat, T.; Özcan, Ş. Interparticle interaction effects on magnetic behaviors of hematite $\left(\alpha-\mathrm{Fe}_{2} \mathrm{O}_{3}\right)$ nanoparticles. Physica B: Condensed Matter, 2011, 406, pp. 2483-2487.

11. Tadić, M.; Marković, D.; Spasojević, V.; Kusigerski V.; Remškar M.; Pirnat J.; Jagličić Z. Synthesis and magnetic properties of concentrated $\alpha-\mathrm{Fe}_{2} \mathrm{O}_{3}$ nanoparticles in a silica matrix. Journal of Alloys and Compounds, 2007, 441(1-2), pp. 291-296.

12. Cornell, R.M.; Schwertmann, U. The Iron Oxides: Structure, Properties, Reactions, Occurrences and Uses. John Wiley \& Sons, 2003, 695p.

13. Wagloehner, S.; Kureti, S. Study on the mechanism of the oxidation of soot on $\mathrm{Fe}_{2} \mathrm{O}_{3}$ catalyst. Applied Catalysis B: Environmental, 2012, 125, pp. 158-165.

14. Khedr, M.H.; Abdel Halim, K.S.; Nasr, M.I.; El-Mansy, A.M. Effect of temperature on the catalytic oxidation of CO over nano-sized iron oxide. Materials Science and Engineering: A, 2006, 430 (1-2), pp. 40-45.

15. Gu, J.; Li, S.; Wang, E.; Li, Q.; Sun, G.; Xu, R.; Zhang, H. Single-crystalline $\alpha-\mathrm{Fe}_{2} \mathrm{O}_{3}$ with hierarchical structures: Controllable synthesis, formation mechanism and photocatalytic properties. Journal of Solid State Chemistry. 2009, 182(5), pp. 1265-1272.

16. Mahajan, D.; Gütlich, P.; Stumm, U. The role of nano-sized iron particles in slurry phase Fischer-Tropsch synthesis. Catalysis Communications, 2003, 4(3), pp. 101-107.

17. Nguyen, D.C.; Nguyen, D.H.; Tran, T.H.; Dinh, Q.K.; Duong, T.Q.; Vu V. Q.; Nguyen, V.H. Nanoporous hematite nanoparticles: Synthesis and applications for benzylation of benzene and aromatic compounds. Journal of Alloys and Compounds, 2014, 585(5), pp.83-87.

18. Covalev, V.V.; Turta K.I.; Band, M.I. Investigation of the phase composition of the precipitate formed in electrochemical cleaning hot wastewater. Izvestie AN MSSR, Biological and Chemical Engineering Sciences, 1985, 2, pp. $42-48$ (in Russian).

19. Le Formal, F.; Grätzel, M.; Sivula K. Controlling Photoactivity in Ultrathin Hematite Films for Solar WaterSplitting. Advanced Functional Materials, 2010, 20, pp. 1099-1107.

20. Abdulkadir, I.; Aliyu, A.B. Some wet routes for synthesis of hematite nanostructures. African Journal of Pure and Applied Chemistry, 2013, 7(3), pp. 114-121.

21. Han, L.-H.; Liu, H.; Wei, Y. In situ synthesis of hematite nanoparticles using a low-temperature microemulsion method. Powder Technology, 2011, 207, pp. 42-46.

22. Bhattacharjee, A.; Rooj, A.; Roy, M.; Kusz, J.; Gutlich, P. Solventless synthesis of hematite nanoparticles using ferrocene. Journal of Materials Science, 2013, 48, pp. 2961-2968.

23. Woo, K.; Lee H.J. Synthesis and magnetism of hematite and maghemite nanoparticles. Journal of Magnetism and Magnetic Materials, 2004, 272-246, pp. E1155-E1156.

24. Borzi, R.A.; Stewart, S.J.; Punte, G.; Mercader, R.C.; Vasquez-Mansilla, M.; Zysler, R.D.; Cabanillas, E.D. Magnetic interactions in hematite small particles obtained by ball milling. Journal of Magnetism and Magnetic Materials, 1999, 205, pp.234-240.

25. Ahmmad, B.; Leonard, K.; Islam, Md. S.; Kurawaki, J.; Muruganandham, M.; Ohkubo, T.; Kuroda, Y. Green synthesis of mesoporous hematite $\left(\alpha-\mathrm{Fe}_{2} \mathrm{O}_{3}\right)$ nanoparticles and their photocatalytic activity. Advanced Powder Technology, 2013, 24, pp. 160-167.

26. Bang, J.H.; Suslick, K.S. Sonochemical Synthesis of Nanosized Hollow Hematite. Journal of the American Chemical Society, 2007, 129, pp. 2242-2243

27. Marinović-Cincović, M.;Wang, G.;Fedoroff, M.; Šaponjić,Z.V.; Milonjić, S.K.; Nedeljković, J.M. Ferricoxychloride and Hematite Nanoparticles: Synthesis and Phase Transformation. Materials Science Forum, 2006, 518, pp. 63-66. 
28. Oćwieja, M.; Adamczyk, Z.; Morga, M.; Bielanska, E.; Wegrzynowicz, A. Hematite nanoparticle monolayers on mica preparation by controlled self-assembly. Journal of Colloid and Interface Science, 2012, 386, pp. 51-59.

29. Zhu, M.; Wang, Y.; Meng, D.; Qin, X.; Diao, G. Hydrothermal Synthesis of Hematite Nanoparticles and Their Electrochemical Properties. The Journal of Physical Chemistry C, 2012, 116, pp. 16276-16285.

30. Sreeram, K.J.; Nidhin, M.; Nair, B.U. Synthesis of aligned hematite nanoparticles on chitosan-alginate films. Colloids and Surfaces B: Biointerfaces, 2009, 71, pp. 260-267.

31. Turta, K.I.; Shova, S.G.; Spatari, E.A.; Mazus, M.D.; Malinovskii, T.I. Crystal and molecular structure, electron structure of iron(III) carboxylate. Zhurnal Strukturnoi Khimii, 1994, 35, pp. 112-120 (in Russian).

32. Rendon, J.L.; Serena, C. J. IR spectra of powder hematite: effects of particle size and shape. Clay Minerals, 1981, 16, pp. 375-381.

33. Abramoff, M.D.; Magalhaes, P.J.; Ram, S.J. Image Processing with ImageJ. Biophotonics International, 2004, 11(7), pp. 36-42.

34. Downs, R.T. The RRUFF Project: an integrated study of the chemistry, crystallography, Raman and infrared spectroscopy of minerals. Program and Abstracts of the 19th General Meeting of the International Mineralogical Association in Kobe, Japan, 2006, O03-13.

35. Patterson, A.L. The Scherrer formula for X-Ray particle size determination. Physical Review, 1939, 56, pp. 978982.

36. Jubb, A. M.; Allen, H. C. Vibrational spectroscopic characterization of hematite, maghemite, and magnetite thin films produced by vapor deposition. Applied Materials \& Interfaces, 2010, 2(10), pp. 2804-2812.

37. de Faria, D.L.A.; Silva, S.V.; de Oliveira M.T. Raman microspectroscopy of some iron oxides and oxyhydroxides. Journal of Raman Spectroscopy, 1997, 28, pp. 873-878. 